\title{
Analysis The Effect of Total Quality Management, Technology, and Knowledge Management on Product Quality in Indonesia Construction Industry
}

\author{
Mohammad Yogie Latansa ${ }^{1}$, Tri Joko Wahyu Adi $^{2}$ and Mohammad Arif Rohman ${ }^{2}$
}

\begin{abstract}
The construction industry is being faced with rapid development with a high level of competition. In the current global competition, construction companies must be able to compete in order to meet customer demand and satisfaction. In response to the competition, construction companies must efforts to develop products and services. In the development process knowledge management has a role in improving quality. In addition, the use of technology and the implementation of total quality management through knowledge management can improve quality. Quality is the main factor in order to develop products and services to encourage sustainable achievement. This research aims to analyze the factors that influence technology, implementation of total quality management, and knowledge management on the product construction quality in Indonesia. The data used in this research are primary data. The factor identification process is carried out by distributing questionnaires to contractors which involved in the construction industry in Indonesia as respondents. Furthermore, the data obtained were analyzed using the relative importance index ( RII) to obtain a sequence of factors that influence. Then the influencing factors analyzed using structural equation modelling (SEM) with SPSS statistical software. This research expected to resulting models of factors that influence technology, implementation of total quality management, and knowledge management on product construction quality in Indonesia.
\end{abstract}

Keywords-Technology, Implementation of Total Quality Management, Knowledge Management, Quality, Structural Equation Modelling (SEM).

\section{INTRODUCTION}

The construction industry is experiencing rapid development with a high level of competition. In the current global competition, construction companies must be able to compete to meet customer demand and satisfaction. In response to the competition, construction companies must regenerate to develop products, services, productivity and processes constantly. In the framework of the development process the company must update its hardware technology and business processes. The

${ }^{1}$ Mohammad Yogie Latansa is with Departement of Business and Management Technology, Institut Technology Sepuluh Nopember, Surabaya, Indonesia. E- mail: yogie.latansa@gmail.com.

${ }^{2}$ Tri Joko Wahyu Adi and Mohammad Arif Rohman are with Departement of Civil Engineering, Institut Technology Sepuluh Nopember, Surabaya, Indonesia. E- mail: tri_joko@ce.its.ac.id; arif@ce.its.ac.id. company's regenerative process can be achieved through technology development and transfer.

The future of the Indonesian construction industry relies heavily on its ability to anticipate, respond to problems, and see opportunities. The biggest problem that is being faced is the problem of globalization, decentralization, the development of professional workforce, shortages of skilled workers, and the lack of collaboration among national construction service actors so that it affects productivity. Productivity in the construction industry influences work results or quality. One way to increase productivity is through the application of technology in the construction process.

Technology plays an important role in increasing the productivity of the construction industry. Construction service entrepreneurs try to realize the project without ignoring the achievement of cost and time efficiency while still meeting quality. The selection of a method is very important in the implementation of a construction project because the right implementation method can provide maximum results, especially if it is reviewed in terms of costs and in terms of time. With the increasingly rapid technological advancements in the construction industry, it allows project managers to choose one method of implementing certain constructions from several alternatives or the choice of methods of implementation of existing constructions. One of the efforts made by project managers is to replace conventional ways to become more modern.

One of the challenges when discussing the topic of technology in the construction industry is that there are different interpretations of technology in related stakeholders. For example, designers assume that construction technology is a way to automate project plans and designs, while contractors consider that technology is using robots to do tasks at project sites (eg concrete blasting robots, robot fireproof coatings, and robot painting bridges).

The process of getting technology can be done in two ways, namely: technological innovation and technology transfer. Technological innovations in the construction industry are carried out by construction service companies primarily to obtain new construction methods that are able to overcome obstacles in the field and materials that have better strength, reduce the weight of structural materials or 
are easier and faster to do. In general, innovation is done incrementally, namely innovation by making a few changes or gradually to achieve better quality.

Technology transfer takes place through all three lines, namely the general route, engineering lines, and planned routes. In software components, technology transfer that occurs in general through a planned path where technology suppliers allow the technology to be used by buying usage rights or licenses. Industries applying technology to construction projects aim to support the achievement of quality and reduce product development costs. Knowledge Management is a scientific discipline that includes systematic techniques used to obtain information, transfer processes, and information management in an organization. Knowledge Management is a process that facilitates all activities related to knowledge, such as creation, transformation, and how to use knowledge [1]. An important step in the process of implementing knowledge is to link knowledge management with the company's business targets. The aim of Knowledge Management is to form a "learning organization" that can evaluate, store, use, and commercialize knowledge that is within the scope of the organization. An important step in the process of implementing knowledge is combining Knowledge Management and organizational business targets.

Examined the problem of effective Knowledge Management when viewed from the perspective of organizational capability [2]. This perspective suggests that knowledge of infrastructure includes technology knowledge, structural knowledge, and culture. The results of this study provide a basis for understanding the competitive predisposition of an organization when implementing Knowledge Management [3]. also argue that Knowledge Management consists of three interrelated processes, namely: knowledge acquisition, knowledge conversion, and knowledge application. Capability Knowledge Management refers to the process of developing and using knowledge in an organization.

Knowledge Management is also related to how to obtain, share, develop and use knowledge that produces added value for the organization. Knowledge itself is categorized as something structured, unstructured, explicit or implicit. If knowledge is organized and easily organized, it is called structured knowledge. Knowledge that is unstructured and understood, but not clearly stated is implicit knowledge. Implicit knowledge is also called tacit, which is the expertise and experience of workers who have not been formally documented [4].

The process of identifying and determining the role of each member for the implementation of knowledge in each organizational process is importan $\mathrm{t}[5]$. The following are the objectives and expected results of the Knowledge Management process in the organizatio [5]:

- To improve performance, productivity, and organizational competition.
- To obtain, share and use knowledge in the organization effectively.

- To develop a decision system in the organization

- To develop processes and and to obtain good application

- To reduce research costs and delays.

Quality is one of the instruments in competing. Thus, the company has noticed that quality is the main important factor for developing products and services to encourage sustainable achievement [6]. Technology enables companies to develop high quality products and services.

The organization strives to produce high-quality products for consumers. Organizations through quality departments determine the quality and direction of a product in a production system. In addition, the quality department's responsibility is to determine whether consumers are satisfied enough or whether it is in accordance with the organization's target [7].

Total Quality Management (TQM) has an important role to foster competitiveness of companies in local and international markets. All departments within the company are directed to work together to achieve goals in order to achieve success in the market. Total Quality Management (TQM) is a management system and is also a philosophy of a company that can develop a company's competitiveness. Total Quality Management (TQM) also brings more effective changes to organizations with the following strategies [8][9]

- Change organizational culture.

- To involve relevant parties in order to reach the target organization.

- Education and training.

- To ensure sustainable development (focusing on organizational targets in general rather than individual achievements).

- Identifying internal and external consumers (building strong communication with suppliers and consumers so as to focus on developing product quality and purchasing policies rather than prices).

- To measure and display products and data in the process.

- To strengthen relationships between individuals in processes related to quality.

In accordance with the above phenomena, researchers suspect that technology variables, TQM implementation, and knowledge management can be a booster to increase product quality in the high rise building construction industry in Indonesia. In this study researchers propose a structural model that is formed through exogenous variables and endogenous variables measured by several indicators. So that this research needs to be done to test theories based on previous research and to test the structural models proposed by researchers.

This study is a type of confirmatory factor analysis study that was directly carried out in the field to obtain primary data through questionnaires. In this study the variables used are technology, TQM implementation, knowledge management, and quality. These variables are measured by 
several indicators that have been used in previous studies. Indicators on technology variables are: technology management, $\mathrm{R}$ \& $\mathrm{D}$ management, and technology management. The indicators for the TQM implementation variables are continuous improvement, teamwork, customer focus, and leadership. The indicators used to measure knowledge management variables are knowledge sharing, information technology support, knowledge development, organizational culture, and knowledge applicaton. While the indicator used to measure the quality variable is the project financing process, on time delivery, minimum waste, availability of plants \& equipment, and product standardization. Each of these indicators will then be translated by the researcher into a statement measured using a Likert scale.

\section{METHOD}

This study was conducted to test the hypotheses intended by using research methods that have been designed with the variables studied in order to obtain accurate results. The discussion in this research method includes research design, research boundaries, theoretical thinking framework, hypothesis formulation, variable measurement, variable identification, population, sample, and sampling techniques, research instruments, data, and collection methods, validity and reliability tests, and those that the last is data analysis techniques.

\section{A. Research Design}

This study aims to examine whether the indicators that have been grouped based on latent variables remain in the construct or not. In this study the researchers developed six hypotheses from the four variables based on the theoretical framework or previous research proposed by reference. The researcher tested whether fit data with hypotheses that have been formed before or not, so this study is a confirmatory factor analysis study. When viewed from the data sources obtained in this study, this study is categorized as primary research. Research with primary data sources is data obtained or derived from the first party that owns a data. If seen from the method of data collection, this study is categorized as questionnaire research. Questionnaires are primary data collection methods that use a number of structured question items with specific format questions. When viewed from the purpose of this study, it is categorized as a correlational study. Correlational studies are studies conducted to be able to see whether or not there is a relationship between the variables studied. Based on the measurement and analysis of research data, it is a qualitative study, namely research whose data is expressed in verbal form and analyzed using statistical techniques. Based on the place of research, is a field research (field research), namely research that is directly carried out in the field or to respondents.

\section{B. Research Stages}

Stages of research include identification of research variables and indicators, preparation of research questionnaires, testing of validity and reliability of data, distribution of questionnaires, analysis of structural equation modeling (SEM), discussion, conclusions and suggestions. The scope of this study is limited to employees of several companies engaged in construction (contractors) with the variables studied are the implementation of total quality management, technology, knowledge management, and quality.

\section{Identification of Research Variables and Indicators}

In this research looking for the relationship of the influence of independent / independent variables, with intervening variables on non-dependent / dependent variables and indicators that influence it. The reasearch models proposed shown in Figure 1.

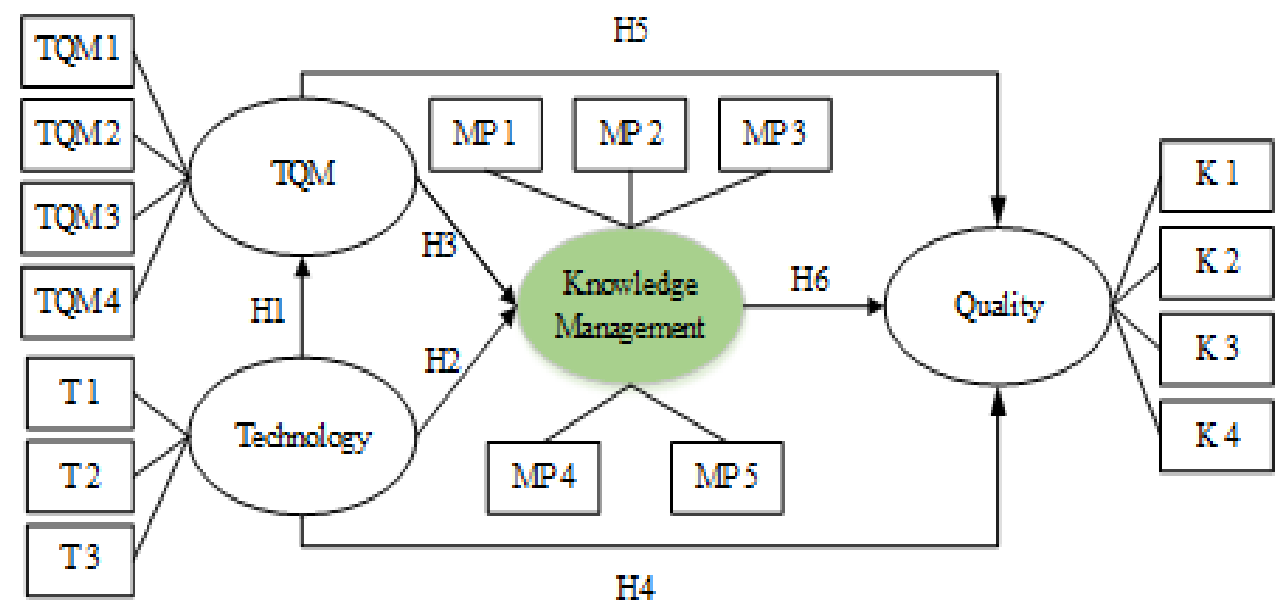

Figure 1. Research model. 


\section{Survey Instrument}

The questionnaire encompasses questions about four constructs. These constructs are total quality management (TQM), technology, knowledge management, and quality. Then, this variables measured by indicator which based on review of literature. The measured indicator shown in Table 1. Respondents were asked to evaluate their firm's on five point Likert scale.

\section{E. Hypotheses Development}

In this section, researchers propose a theoretical framework taken based on the results of literature and previous research. The theoretical thinking framework proposed includes technology variables, implementation of Total Quality Management (TQM), knowledge management, and quality. Based on the theoretical framework described, the hypothesis proposed research are:

H1: There is positive relationship between technology and TQM implementation.

$\mathrm{H} 2$ : There is positive relationship between technology and knowledge management.

H3: There is positive relationship between TQM implementation and knowledge management.

H4: There is positive relationship between technology and quality.

H5: There is positive relationship between TQM implementation and quality.

H6: There is positive relationship between knowledge management and quality

TABLE 1 .

MEASURED INDICATOR FROM EACH LATENT VARIABLES

\begin{tabular}{|c|c|c|c|}
\hline No & Indicator & Explanation & References \\
\hline \multirow[t]{3}{*}{1} & $\mathrm{~T} 1$ & Technology management & \multirow{3}{*}{$\begin{array}{l}\text { Prajogo, 2006; Brah, } \\
\text { 2006; }\end{array}$} \\
\hline & $\mathrm{T} 2$ & R\&D Management & \\
\hline & T 3 & Technology performance & \\
\hline \multirow[t]{4}{*}{2} & TQM 1 & Continous improvement & \multirow{4}{*}{$\begin{array}{l}\text { Zehir, 2012; Prajogo, } \\
\text { 2001; Mohammed, } \\
\text { 2012; Cetindere, 2015; } \\
\text { Al-shdaifat, 2015; Brah, } \\
\text { 2006; Prajogo, 2006 }\end{array}$} \\
\hline & TQM 2 & Teamwork & \\
\hline & TQM 3 & Customer focus & \\
\hline & TQM 4 & Leadership & \\
\hline \multirow[t]{6}{*}{3} & MP 1 & Knowledge sharing & \multirow{6}{*}{$\begin{array}{l}\text { Valmohammadi, 2015; } \\
\text { Hu, 2018; Abubakar, } \\
\text { 2017; Mahdi, 2018; } \\
\text { Santoro, 2017; }\end{array}$} \\
\hline & MP 2 & Information technology & \\
\hline & MP 3 & support & \\
\hline & MP 4 & Knowledge application & \\
\hline & MP 5 & Developing knowledge & \\
\hline & & Organizarional culture & \\
\hline \multirow[t]{4}{*}{4} & K 1 & Cost of Quality & \multirow{4}{*}{$\begin{array}{l}\text { Abubakar, 2017; } \\
\text { Bolatan,2016; Battikha, } \\
\text { 2003; Jose, 2017; Jha, } \\
\text { 2006; Jha, 2009; Leong, } \\
2014\end{array}$} \\
\hline & $\mathrm{K} 2$ & On time delivery & \\
\hline & K 3 & Minimum waste & \\
\hline & K 4 & Product standardization & \\
\hline
\end{tabular}

TABLE 2.

MEASURED INDICATOR FROM EACH LATENT VARIABLES

\begin{tabular}{lcc}
\hline \hline Goodness of Fit Measurement & Indikator & Loading factor \\
\hline Teknologi & & \\
\hline Chi-square $=0,00$ & $\mathrm{~T} 1$ & 0,68 \\
& $\mathrm{~T} 2$ & 0,79 \\
$\mathrm{p}=-$ & $\mathrm{T} 3$ & 0,78 \\
\hline $\mathrm{TQM}$ & & \\
\hline Chi-square $=0,471$ & $\mathrm{TQM} 1$ & 0,68 \\
& $\mathrm{TQM} 2$ & 0,87 \\
$\mathrm{p}=0,790>0,05$ & $\mathrm{TQM} 3$ & 0,74 \\
& $\mathrm{TQM} 4$ & 0,77 \\
\hline Manajemen pengetahuan & & \\
\hline Chi-square $=10,257$ & $\mathrm{MP} 1$ & 0,68 \\
& $\mathrm{MP} 2$ & 0,62 \\
$\mathrm{p}=0,68>0,05$ & $\mathrm{MP} 3$ & 0,89 \\
& $\mathrm{MP} 4$ & 0,81 \\
& $\mathrm{MP5}$ & 0,54 \\
\hline Kualitas & & \\
\hline Chi-square $=4,308$ & $\mathrm{~K} 1$ & 0,151 \\
$\mathrm{p}=0,116>0,05$ & $\mathrm{~K} 2$ & 0,716 \\
\hline \hline
\end{tabular}

\section{RESULTS AND DISCUSSION}

\section{A. Confirmatory Factor Analysis Each Latent Variables}

The results of confirmatory factor analysis form each latent variable are summarized in Table 2. The results of data processing show that all constructs used to form a research model, in the confirmatory factor analysis process have met the established goodness of fit criteria. The probability value in this analysis shows a value above the significance limits of 0.05 .

From the results of processing the data, it can be seen also the value of the loading factor of each indicator forming a latent variable. The value of the loading factor shows good results if it is greater than 0.5 . However, the $\mathrm{K} 1$ indicator has a lower loading factor of $0.5(0.151<0.5)$, so it can be considered to be remove.

\section{B. Full Model Confirmatory Factor Analysis}

The result of data processing for full model analysis as shown in Figure 2. The test of model feasibility shows that this model is in accordance with the data or fit to the data used with the aim of knowing the magnitude of the effect as shown in Table 3. The results of the data processing analysis show that all constructs used to form a research model, in the confirmatory factor analysis process have not met the established criteria for goodness of fit. 


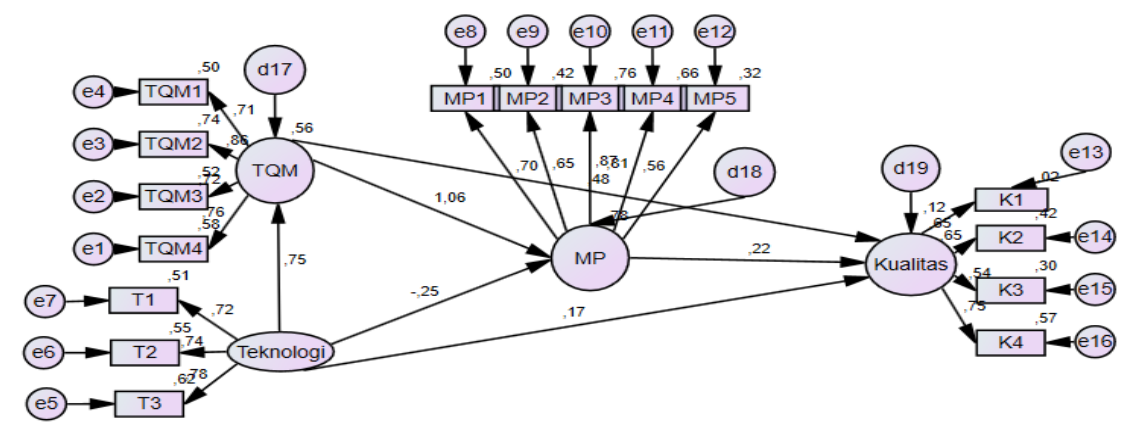

Figure 2. Full model analysis result.

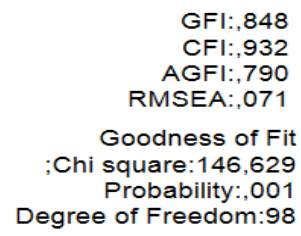

The probability value in this analysis shows a value above the significance limit of $0.001(\mathrm{p}<0.05)$, this value indicates a difference between the sample covariance matrix and the estimated population covariance matrix, so it is necessary to test the data. To get a good model, the problem of deviation from the assumption of Structural Equation Modeling (SEM) is tested first.

TABLE 3.

Results of The Data PROCESSING ANaLysis

\begin{tabular}{cccc}
\hline \hline $\begin{array}{c}\text { Goodness of Fit } \\
\text { Index }\end{array}$ & $\begin{array}{c}\text { Cut-off } \\
\text { Value }\end{array}$ & $\begin{array}{c}\text { Analyze } \\
\text { Result }\end{array}$ & $\begin{array}{c}\text { Model } \\
\text { Evaluation }\end{array}$ \\
\hline CMIN/DF & $\leq 2.00$ & 1.49 & Good \\
Probability & $\geq 0.05$ & 0.001 & Not good \\
RMSEA & $\leq 0.08$ & 0.071 & Good \\
GFI & $\geq 0.90$ & 0.848 & Marginal \\
AGFI & $\geq 0.90$ & 0.790 & Marginal \\
TLI & $\geq 0.95$ & 0.917 & Marginal \\
CFI & $\geq 0.95$ & 0.932 & Marginal \\
\hline \hline
\end{tabular}

C. Evaluation of Normality Data

Skewness is a measurement of the symmetry of data distribution, while kurtosis is a measurement of data distribution discrepancies (Tabachnick \& Fidell, 2007). The assumption of normality of the data is tested by looking at the value of skewness and kurtosis from the data used. If the $\mathrm{CR}$ value of skewness and kurtosis of the data is in the range between \pm 3.00 , then the data can still be stated as distributed at the 0.01 significance level [10]. The results of testing the normality of data can be seen in Table 4. The results of testing the normality of data in table 4 using IBM SPSS 21 software shows that there is no indicator with a CR value (statistical skewness \& statistical kurtosis) that is outside the range of \pm 3.00 . Thus the research data used has met the requirements for normality of data, or it can be said that the research data has been normally distributed. Thus the assumption of normal data in this case can be fulfilled.
Furthermore, if the data analyzed is normal spread with a large sample size (100), then the normal data assumption is not too critical, the basis is Central Limit Teorm which is if the sample size is large, then the statistics of the large sample will approach the distribution normal even though the population of the sample is not normally distributed.

\section{Outliers}

Outliers are cases that have a score score or indicator of variables or indicators that are higher or lower than other cases [10]. Outliers can be evaluated in two ways, namely analysis of univariate outliers and analysis of multivariate outliers [11]. Testing whether there are univariate outliers is done by analyzing the $\mathrm{Z}$ score from the research data used [12]. If there is a $Z$ score in the range of $\geq 3$, it will be categorized as outliers. Furthermore, evaluating univariate outliers using IBM SPSS 21 software. The results of data processing for testing the existence of univariate outliers are in Table 4. Evaluation of multivariate outliers is done by evaluating the value of the distance of Mahalanobis (Mahalanobis Distance) for each observation. Based on the chi-square value (X2) with free degree (df) 16 (number of indicators in the study) with a significance level of 0.001 , the mahalanobis distance is 39.25 .

\section{E. Multicollienarity and Singularity}

The next data testing is to see whether there is multicollinearity and singluaritas in a combination of variables, so what must be considered is the determinant value of the sample covariance matrix. The presence of multicolinerity and singularity can be seen through the determinants of truly small covariance matrices, or close to zero. From the results of data processing through AMOS the value of the sample covariance matrix determinant is 0,000 . These results indicate that the value of the sample covariance matrix determinant is 0 , so that there is multicollinarity and singularity in the data. 
TABLE 3.

NORMALLITY DATA TESTING

\begin{tabular}{|c|c|c|c|c|c|c|c|c|c|}
\hline \multicolumn{10}{|c|}{ Descriptive Statistics } \\
\hline & $N$ & Minimum & Maximum & Mean & Std. Deviation & & vness & & tosis \\
\hline & Statistic & Statistic & Statistic & Statistic & Statistic & Statistic & Std. Error & Statistic & Std. Error \\
\hline $\mathrm{T} 1$ & 100 & 1 & 5 & 3,60 & ,964 &,- 497 &, 241 & ,436 & ,478 \\
\hline $\mathrm{T} 2$ & 100 & 1 & 5 & 3,38 & 1,144 &,- 297 & ,241 &,- 541 & ,478 \\
\hline $\mathrm{T} 3$ & 100 & 1 & 5 & 3,61 & ,963 &,- 458 & ,241 &,- 159 & ,478 \\
\hline TQM1 & 100 & 1 & 5 & 3,87 &, 861 &,- 812 & ,241 & 1,241 & ,478 \\
\hline TQM2 & 100 & 1 & 5 & 4,30 &, 823 & $-1,388$ &, 241 & 2,461 & ,478 \\
\hline TQM3 & 100 & 1 & 5 & 4,15 & 880 & $-1,297$ & ,241 & 2,266 & ,478 \\
\hline TQM4 & 100 & 1 & 5 & 4,12 & ,913 & $-1,379$ & ,241 & 2,551 & ,478 \\
\hline MP1 & 100 & 2 & 5 & 4,32 & ,764 & $-1,034$ & ,241 &, 839 & ,478 \\
\hline MP2 & 100 & 2 & 5 & 3,99 & ,927 &,- 602 & ,241 &,- 485 & ,478 \\
\hline MP3 & 100 & 1 & 5 & 4,11 &, 875 &,- 864 & ,241 & ,646 & ,478 \\
\hline MP4 & 100 & 1 & 5 & 4,19 & ,813 & $-1,055$ & ,241 & 1,642 & ,478 \\
\hline MP5 & 100 & 1 & 5 & 4,02 & ,899 & $-1,062$ & ,241 & 1,477 & ,478 \\
\hline K1 & 100 & 1 & 5 & 3,28 & 1,006 & ,017 & ,241 &,- 719 & ,478 \\
\hline K2 & 100 & 1 & 5 & 3,47 & 1,000 &,- 195 & ,241 &,- 293 & ,478 \\
\hline K3 & 100 & 1 & 5 & 3,50 & 1,059 &,- 391 & ,241 &,- 385 & ,478 \\
\hline K4 & 100 & 1 & 5 & 4,02 & ,943 & $-1,148$ &, 241 & 1,628 & ,478 \\
\hline Valid N (listwise) & 100 & & & & & & & & \\
\hline
\end{tabular}

TABLE 4.

UNIVARIATE OUTLIERS TESTING

\begin{tabular}{lccccc}
\hline \hline Descriptive Statistics & & & & & \\
\hline & $\mathbf{N}$ & Minimum & Maximum & Mean & Std. Deviation \\
\hline Zscore(T1) & 100 & $-269,710$ & 145,228 &, 0000000 & $100,000,000$ \\
Zscore(T2) & 100 & $-208,046$ & 141,611 &, 0000000 & $100,000,000$ \\
Zscore(T3) & 100 & $-271,057$ & 144,356 &, 0000000 & $100,000,000$ \\
Zscore(TQM1) & 100 & $-333,517$ & 131,315 &, 0000000 & $100,000,000$ \\
Zscore(TQM2) & 100 & $-401,138$ &, 85090 &, 0000000 & $100,000,000$ \\
Zscore(TQM3) & 100 & $-357,758$ &, 96538 &, 0000000 & $100,000,000$ \\
Zscore(TQM4) & 100 & $-341,655$ &, 96364 &, 0000000 & $100,000,000$ \\
Zscore(MP1) & 100 & $-303,733$ &, 89025 &, 0000000 & $100,000,000$ \\
Zscore(MP2) & 100 & $-214,776$ & 109,007 &, 0000000 & $100,000,000$ \\
Zscore(MP3) & 100 & $-355,445$ & 101,719 &, 0000000 & $100,000,000$ \\
Zscore(MP4) & 100 & $-392,512$ &, 99666 &, 0000000 & $100,000,000$ \\
Zscore(MP5) & 100 & $-336,038$ & 109,045 &, 0000000 & $100,000,000$ \\
Zscore(K1) & 100 & $-226,676$ & 171,001 &, 0000000 & $100,000,000$ \\
Zscore(K2) & 100 & $-247,112$ & 153,070 &, 0000000 & $100,000,000$ \\
Zscore(K3) & 100 & $-236,100$ & 141,660 &, 0000000 & $100,000,000$ \\
Zscore(K4) & 100 & $-320,392$ & 103,968 &, 0000000 & $100,000,000$ \\
Valid N (listwise) & 100 & & & & \\
\hline
\end{tabular}

Furthermore, to strengthen the analysis of the data, researchers used IBM SPSS 21 software to determine the value of sample covariance matrix determinants through tolerance values and Variance Inflation Factor (VIF). The results of processing data using IBM SPSS software are in Table 5.

\section{F. Standardized residual covariance}

Interpretations and modifications are intended to see what the model is developed in this study, it needs to be 
modified or changedso that you get a better model. A research model said to be good if it has the value of Standardized Residual Covariance in it standard set $(\leq \pm$ 2.58). The results of the analysis on each relationship between indicators of this study do not indicate the existence of standardized residual covariance values that are outside the range of \pm 2.58 values. So by looking at these results, there is no need to modify the research model.

\section{G. Reliability and variance extract}

Reliability testing shows the extent to which a measuring instrument can give results that are relatively the same if measurements are taken again at the same object. The minimum reliability value from the variable forming variable latent that can be received is equal to 0.70 . The variance extract measurement shows the number of variances of the indicators extracted by the latent constructs / variables developed. Acceptable variance extract values are a minimum of $0.50(>0.50)$. Based on observations in Table 6 it appears that four latent variables meet the reliability requirements (CR) and variance extract (VE), namely Technology, TQM, and Knowledge Management. However, the quality variable is a large CR value of 0.61 , where this value is still in the marginal category. Then the value of VE on the Quality variable is 0.32 . The VE value obtained is smaller than the reliability requirement $(\mathrm{VE} \leq 0.50)$. However, the use of $\mathrm{VE}$ in measuring reliability is optional or not required (Hair,
2006). So, the researcher focuses on the reliability test of latent variables on the value of $\mathrm{CR}$.

\section{H. Discussion}

The parameter estimation of the relationship between Technology and TQM implementation obtained a value of 0.684 . Testing the relationship between the two variables shows the value $C . R=4,884$ with probabilities $<0.05$. So it can be concluded that the Technology variable has a positive and significant effect on the TQM implementation variable, so if the level of TQM implementation is higher, the product quality will also be higher. This is reinforced by the results of data processing that shows a probability value of less than 0.05 and a C.R value of 4.884 has met the requirements of .91 .96 . Furthermore, the biggest loading factor value is 0.79 which is a T2 (R \& D management) indicator.

The results of this study indicate that Technology does not have a significant effect on Knowledge Management. In this case, even though the company has an innovative $\mathrm{R}$ \& D department but is not supported by a good Knowledge Management system, it cannot significantly increase the level of product quality. In accordance with the testing and processing of data, the relationship between Technology variables with the Knowledge Management variable is not significant. This if it is linked between the theory and the real situation in the field, the implication is that the respondent did not use the latest technology when carrying out the construction process of the building.

TABLE 5 .

VALUE OF SAMPLE COVARIANCE MATRIX

\begin{tabular}{|c|c|c|c|c|c|c|c|}
\hline \multicolumn{8}{|c|}{ Coefficients $^{\mathrm{a}}$} \\
\hline \multirow{2}{*}{ Model } & \multicolumn{2}{|c|}{ Unstandardized Coefficients } & \multirow{2}{*}{$\begin{array}{c}\text { Standardized Coefficients } \\
\text { Beta }\end{array}$} & \multirow{2}{*}{$t$} & \multirow{2}{*}{ Sig. } & \multicolumn{2}{|c|}{ Collinearity Statistics } \\
\hline & $\boldsymbol{B}$ & Std. Error & & & & Tolerance & $V I F$ \\
\hline (Constant) & $-1.08 \mathrm{E}-10$ &, 000 & &, 000 & 1,000 & & \\
\hline $\mathrm{T} 1$ & 1,000 & 000 &, 101 & $92,695,295,589$ &, 000 &, 500 & 2,001 \\
\hline $\mathrm{T} 2$ & 1,000 &, 000 &, 120 & $108,419,812,450$ &, 000 & ,486 & 2,060 \\
\hline $\mathrm{T} 3$ & 1,000 &, 000 &, 101 & $84,673,141,328$ &, 000 & ,418 & 2,392 \\
\hline TQM1 & 1,000 &, 000 &, 091 & $79,326,068,638$ &, 000 & ,459 & 2,177 \\
\hline TQM2 & 1,000 &, 000 &, 087 & $60,882,660,624$ &, 000 & ,296 & 3,378 \\
\hline TQM3 & 1,000 &, 000 & ,093 & $80,896,444,572$ &, 000 &, 456 & 2,191 \\
\hline TQM4 & 1,000 &, 000 & ,096 & $78,381,802,288$ &, 000 & ,398 & 2,511 \\
\hline MP1 & 1,000 &, 000 &, 080 & $73,003,466,289$ &, 000 & ,494 & 2,025 \\
\hline MP2 & 1,000 & ,000 &, 097 & $86,363,570,209$ &, 000 & ,470 & 2,129 \\
\hline MP3 & 1,000 &, 000 & ,092 & $61,607,639,809$ &, 000 & ,268 & 3,731 \\
\hline MP4 & 1,000 &, 000 &, 086 & $65,311,532,231$ &, 000 &, 349 & 2,865 \\
\hline MP5 & 1,000 &, 000 &, 095 & $85,125,101,590$ &, 000 & ,485 & 2,062 \\
\hline K1 & 1,000 &, 000 & ,106 & $126,071,792,962$ &, 000 &, 849 & 1,178 \\
\hline K2 & 1,000 &, 000 &, 105 & $101,749,031,700$ &, 000 &, 560 & 1,785 \\
\hline K3 & 1,000 &, 000 &, 111 & $119,317,626,447$ &, 000 & ,686 & 1,457 \\
\hline K4 & 1,000 &, 000 & ,099 & $89,026,677,080$ &, 000 & ,482 & 2,074 \\
\hline
\end{tabular}


TABLE 6.

RELIABILITY AND VARIANCE EXTRACT

\begin{tabular}{|c|c|c|c|c|c|c|c|}
\hline No & Variabel & Indikator & Loading factor & $(\text { Loading factor })^{2}$ & Error & C.R & $V E$ \\
\hline \multirow[t]{5}{*}{1} & Teknologi & $\mathrm{T} 1$ & 0,72 & 0,51 & 0,45 & 0,77 & 0,53 \\
\hline & & $\mathrm{T} 2$ & 0,74 & 0,55 & 0,58 & & \\
\hline & & $\mathrm{T} 3$ & 0,72 & 0,51 & 0,35 & & \\
\hline & & & 2,18 & 1,58 & 1,38 & & \\
\hline & & & 4,73 & & & & \\
\hline \multirow[t]{6}{*}{2} & TQM & TQM 1 & 0,71 & 0,50 & 0,36 & 0,89 & 0,66 \\
\hline & & TQM 2 & 0,86 & 0,74 & 0,17 & & \\
\hline & & TQM 3 & 0,77 & 0,60 & 0,37 & & \\
\hline & & TQM 4 & 0,76 & 0,58 & 0,35 & & \\
\hline & & & 3,10 & 2,42 & 1,25 & & \\
\hline & & & 9,64 & & & & \\
\hline \multirow[t]{7}{*}{3} & Manajemen Pengetahuan & MP1 & 0,70 & 0,50 & 0,29 & 0,88 & 0,60 \\
\hline & & MP2 & 0,65 & 0,42 & 0,49 & & \\
\hline & & MP3 & 0,87 & 0,76 & 0,18 & & \\
\hline & & MP4 & 0,81 & 0,66 & 0,22 & & \\
\hline & & MP5 & 0,56 & 0,32 & 0,55 & & \\
\hline & & & 3,60 & 2,65 & 1,73 & & \\
\hline & & & 12,94 & & & & \\
\hline
\end{tabular}

The estimation parameter of the relationship between the TQM implementation variable on the Knowledge Management variable is 0.772 . Testing the relationship between the two variables shows the value of C.R $=4.365$ with a probability level of $<0.05$. Then it can be concluded that the TQM implementation variable significantly influences the Knowledge Management variable. This is caused because the results of data processing indicate a probability value of $<0.05$ and a value of C.R also meets the requirements $\geq 1.96$. The results of this test indicate that the implementation of TQM has a significant effect on Knowledge Management. While the biggest value of loading factor is TQM2 (teamwork).

In accordance with the testing and processing of data, the relationship between technology variables with variable quality is not significant. This if it is linked between the theory and the real condition in the field, the implication is due to finding that the company incurs low costs to produce quality products that comply with the standards.

In accordance with testing and data processing, the relationship between the TQM implementation variable and the Quality variable is not significant. This if it is linked between the theory and the real condition in the field, the implication is because in the field it is that the respondent did not make continuous improvement during the construction process. So as to achieve the expected quality, continuous development must be carried out.

In accordance with testing and processing data, the relationship between Knowledge Management variables with Quality variables is not significant. This if it is related between the theory and the state of the real in the field, the implication is because in the field it is that corporate culture does not support respondents for the knowledge management application process.

\section{REFERENCES}

[1] G. D. Bhatt, "Organizing knowledge in the knowledge development cycle," J. Knowl. Manag., vol. 4, no. 1, pp. 15-26, 2000.

[2] A. H. Gold, A. Malhotra, and A. H. Segars, "Knowledge management: An organizational capabilities perspective," $J$. Manag. Inf. Syst., vol. 18, no. 1, pp. 185-214, 2001.

[3] A. S. Cui, D. A. Griffith, and S. T. Cavusgil, "The influence of competitive intensity and market dynamism on knowledge management capabilities of multinational corporation subsidiaries," J. Int. Mark., vol. 13, no. 3, pp. 32-53, 2005.

[4] K. C. Laudon and J. P. Laudon, Management Information System: Managing The Digital Firm. London, UK: Pearson Education Limited, 2012.

[5] N. Zakaria, A. Amelinckx, and D. Wilemon, "Working together apart? Building a knowledge-sharing culture for global virtual 
The $1^{\text {st }}$ International Conference on Business and Management of Technology (IConBMT)

August 3rd 2019, Institut Teknologi Sepuluh Nopember, Surabaya, Indonesia

E. Boateng-Okrah and F. A. Fening, "TQM implementation: A case of a mining company in Ghana," Benchmarking, vol. 19, no. 6, pp. 743-759, 2012.

[7] B. Lin and K. C. Hidalgo, "Pairing quality assurance and quality control at Frymaster Corporation," Natl. Product. Rev., vol. 18, no. 3, pp. 69-73, 1999.

[8] L. S. Franz and S. T. Foster, "Utilizing a knowledge-based decision-support system as total quality management consultant," Int. J. Prod. Res., vol. 30, no. 9, pp. 2159-2171, 1992.
[9] C. D. Ittner and L. David F., "Choice of information reward systems," J. Account. Res., vol. 33, no. 1995, pp. 1-34, 2015.

[10] R. B. Kline, Principles and Practice of Structural Equation Modeling. New York: The Guilford Press, 2011.

[11] J. F. Hair, W. C. Black, B. J. Babin, and Rolph E. Anderson, Multivariate Data Analysis, 7th ed. New Jersey: Prentice Hal, Inc, 2009.

[12] B. G. Tabachnick and L. S. Fidell, Using Multivariate Statistics. Upper Saddle River, New Jersey: Pearson, 2018. 